\title{
Electrical Conductivity and Chemical Equilibria of Coordination Biopolymeric Cerium (IV)-Alginate Complex with Correlation between the Structure and Complex Stability
}

\author{
Ishaq Zaafarany ${ }^{1}$, Hatem Altass ${ }^{1}$, Jabir Alfahemi ${ }^{1}$, Khalid Khairou ${ }^{1}$, Refat Hassan ${ }^{2}$ \\ ${ }^{1}$ Chemistry Department, Faculty of Applied Sciences, Umm Al-Qura University, Makkah Al-Mukarramah 13401, \\ Saudi Arabia \\ ${ }^{2}$ Chemistry Department, Faculty of Science, Assiut University, Assiut 71516, Egypt \\ Correspondence: Refat Hassan, Chemistry Department, Faculty of Science, Assiut University, Assiut 71516, \\ Egypt. Email: rmhassan2002@yahoo.com, Tel: +201227319979
}

\author{
Received: July1, 2015 Accepted: July15, 2015 Online Published: August 14, 2015 \\ doi:10.5539/ijc.v7n2p57 \\ URL: http://dx.doi.org/10.5539/ijc.v7n2p57
}

\begin{abstract}
In this research study, the cross-linked cerium (IV)-alginate complex, as coordination biopolymeric compound in the granules form, was prepared. It has been indicated from the x-ray diffraction patterns that the nature of alginate complex is amorphous. Additionally, it has been revealed from the infrared absorption spectra that cerium (IV) chelates the alginate macromolecular chains in the complex. The study has displayed that the range of $v_{\mathrm{S}}$ OCO- is $1424 \mathrm{~cm}^{-1}$ and the range of $\mathrm{v}_{\mathrm{aS}} \mathrm{OCO}-$ is $1605 \mathrm{~cm}^{-1}$. This indicates that a complexation type between the cation $\mathrm{Ce}^{4+}$ and both carboxylate and hydroxyl functional groups of alginate macromolecule is usually takes place. The study has also measured the electrical conductivity $(\sigma)$ of coordination biopolymeric cerium (IV)-alginate complex, as function of temperature. It has been indicated from the measured value of the electrical conductivity, i.e., $1.04 \times 10-9$ Siemens at $20^{\circ} \mathrm{C}$ that the conductance of the complex lies in the range of semiconductors. The research has profoundly discussed with evaluation of the thermodynamic parameters. Afterwards, appropriate conduction mechanism based on the electrical conductivity and chemical equilibrium has also been suggested and discussed in terms of the complex stability in correlation with its coordination geometry.
\end{abstract}

Keywords: polymeric biomaterials, chemical equilibria, semiconductors, polysaccharides, geometrical structure, alginates

\section{Introduction}

Alginate is found to be a natural anionic polyelectrolyte of binary linear heteropolymer structure, which consists of 1,4- linked $\alpha$-L-guluronic and $\beta$-D-mannuronic acid units. The monomers are arranged in a clockwise manner fashion around the macromolecular chains (Chanda et al., 1952). Conducting polymers offer the promise of achieving a new generation of polymers and materials that exhibit a high potential application in industrial technology (Nandapureet al., 2013; Kondawaret al., 2011; Jing et al., 2005; Mead, 1961; Sulanecket al., 1990). Coordination biomaterials such as, cited polysaccharides are of great importance in industrial engineering owing to their wide applications in manufacturing and industrial technology, including latex, paint, paper textile, emulsifiers, detergents, stabilizers, as well as in ceramic glaze. They are also used in pharmaceutics of cosmetic like the thickeners, hand lotion, binders, hair, and shampoo components of treatment. They also play an imperative role in the medication as toothpaste binders, ulcer controllers of stomach, and blood antiagulant.

More so, they are also utilized in the industry of food and beverages, such as milk products, pet foods, fish gels, pizza, relishes, jellies, and drinks. In the current era, those polysaccharides as well as their derivatives have become considerably applicable in different applications, including medical adhesive, skin grafting, tissue engineering, drug delivery, biomedical sensors, and in applications of wound dressing.

Conductance measurements of polymers, which are sandwiched between two metal electrodes, have gained considerable attention owing to their wide applications as sensors in electronic devices (El-Dossoukyet al., 1986). Another reason is the acquisition of more information on the structure of materials, which have been achieved from such electrical conductivity measurements. 
Although, conducting polymers, in particular, which are prepared from synthetic polymers, has been the focus of research and development in recent years owing to their unique electrical, optical and chemical properties (Abdel-Wahabet al., 1997).A little attention has been given on the polymers, which are prepared from natural materials, like polysaccharides. This fact may be attributed to the lack of information, which is achieved on the electrical properties of such later materials. Indeed, Hassan and co-workers have also investigated the behavior of electrical conductivity of some coordination natural biopolymers such as, the metal-alginate complexes that are cross-linked, either in the state of granule or gel. For example, the electric conduction as a function of frequency was investigated for coordination biopolymeric metal-alginate compounds in the state of granule or gel form (Abdel-Wahab et al., 1997; Ahmed et al., 1997; Hassanet al., 1989; Hassan, 1989).

Additionally, the electrical conductivities, as a temperature function for some cross-linked complexes of monovalent (Hassan, 1991), divalent (Khairou\& Hassan, 2002), trivalent (Zaafarany et al., 2010; Zaafarany, 2014; Hassan et al., 1995), and hexavalent (Hassan et al., 1993) metal cations, in the forms of granule have also been studied. Unfortunately, the discrepancies and variety of electrical conductivity behavior were observed in those studied complexes and, hence, they made controversial in their suggested conduction mechanisms which became unclear, and incomplete.

After considering the above mentioned aspects of physicochemical studies of natural polymeric biomaterials, the behavior of electrical conductivity of the present complex, may lead the research towards the analysis of the condition of the suggested conduction mechanism. This practice may also help in attaining more information on the relationship of chemical equilibria, electrical properties, and the geometrical structure on the complex stability for these coordination polymeric biomaterial complexes.

\section{Methods and Materials}

\subsection{Experimental Materials}

Sodium alginate, which was used in this study, was Cica-Reagent (Kanto Chem. Co.). In addition to this, all preparations were made by using doubly distilled water. All other materials and resources, which were used in this research, were of analytical grade.

\subsection{Tetravalent Metal alginate}

\subsubsection{Granules Preparation}

The granules of cross-linked Ce (IV)-alginate was formulated and developed via the substitution of the counter ions, $\mathrm{Na}^{+}$, in the alginate macromolecule by the ions of cerium (IV) from the electrolyte (Hassan, 1991; Khairou\& Hassan, 2002; Zaafarany et al., 2010; Zaafarany,2014; Hassan et al., 1995; Hassan et al., 1993). This entire procedure was conducted by gradually adding up the power of alginate to electrolyte solutions of the cerium (IV) ions. During this process, the development of lumps was avoided by ensuring constant and quick stirring of the solution, since formation of such lumps may enhance several complexities. After the accomplishment of the exchange process, the produced granules were gathered and washed thoroughly with de-ionized water. It is significant to notice that the granules were washed so that the ions of non-chelated metal were removed from the resultant water. Afterwards, it was dehydrated under vacuum over anhydrous $\mathrm{P}_{2} \mathrm{O}_{5}$ or $\mathrm{CaCl}_{2}$.Samples were acquired in the form of circular discs, which had the thickness of 1-2 $\mathrm{mm}$ and diameter of 13-14 mm. Those samples were attained by the help of IR disc, which was compressed at a steady pressure of approximately $1500 \mathrm{psi}$.

\subsubsection{X-ray Diffraction}

The patterns of x-ray diffraction were attained by the utilization of a Philip 1710 diffractometer (Hassan, 1991; Khairou\& Hassan, 2002; Zaafarany et al., 2010; Zaafarany,2014; Hassan et al., 1995; Hassan et al., 1993).

\subsubsection{IR Spectra}

In this study, PyeUnicamSp 3100 spectrophotometer was used to scan the IR spectra by utilizing the technique of $\mathrm{KBr}$ disc, having the diameter of $4000-400 \mathrm{~cm}-1$.

\subsubsection{Conductance Measurements}

Metal-alginate complexes, specifically in the gel form, incorporate certain mechanical properties, which complicates the process of measuring their electrical properties through conventional methods. In this situation, a contemporary technique was adopted to overcome such vulnerabilities. Basically, this technique incorporates advanced cell device, which facilitates measurement practices (Hassanet al., 1989; Hassan, 1989; Zaafaranyet al., 2009). 
Moreover, the dc conductance was calculated by the help of Keithely $610 \mathrm{C}$ electrometer, along with the temperature range of approximately 290-560oC.The electrodes having circular shape, which were used for this experiment created a sandwich of M-S-M. In this account, S represents the specimen and M embodies the electrodes. The metal-alginate complex discs were inserted amid the two standard electrodes (silver paste or copper, graphite). The discs were escalated into a formulated electric furnace, which was temperature controlled, and has incorporated a standardized thermocouple of copper-constantan. Furthermore, the acquired or resultant samples were kept short circuited for three to five hours, in order to furnish it for the experimental measurements. The samples were used to measure and estimate the electrical resistance, which was further used to calculate the electrical conductivities $(\sigma)$ as follows:

$$
\sigma=\left(\frac{1}{R}\right)\left(\frac{\mathrm{L}}{\mathrm{a}}\right)
$$

And, R stands for Resistance $(\Omega)$; a stands for the area $(\mathrm{cm} 2)$ of the sample surface, L stands for the Thickness $(\mathrm{cm})$ of the specimen.

\subsubsection{Measurements of Chemical Equilibrium}

Aqueous solutions, incorporating the combinations of hydrogen ions (HCIO4) and the cerium (IV)-alginate complex grains of known concentration were equilibrated thermally within a water-bath of constant temperature. It was upheld at optimum temperature, i.e., $\pm 0.05^{\circ} \mathrm{C}$. It is significant to notice that during this process, a magnetic stirrer was utilized, in order to ensure continuous stirring. After the acquisition of equilibrium, which was attained after $24 \mathrm{~h}$, the solutions found were clear and the reactants contained in them were injected out. More so, the concentration of $\mathrm{Ce}^{4+}$ along with $\mathrm{H}^{+}$was recognized by complexometric and titrimetric techniques (Hassan, 1991; Vogel, 1978).

All tests were repeated, while utilizing different concentrations of the reagents at different scales of temperature. Some experimental runs were performed $\mathrm{pH}$-metrically and conductometrically, in order to analyze and understand the reproducibility of the data, which was acquired from the complexometric and titmetric methods for the determination of the $\left[\mathrm{H}^{+}\right]$and $\left[\mathrm{Ce}^{4+}\right]$, respectively. The acquired results were adequately aligned with each other, as per the predefined experimental error, i.e., $\pm(4-5) \%$. This result confirms the reproducibility of the experimental techniques, which were used in the research study. The results used were also at least an average of five experimental runs. It is significant to notice that by the addition of an inert electrolyte $\mathrm{NaClO} 4$, the ionic force of the mixtures retained their constant value at $0.1 \mathrm{~mol} \mathrm{dm}-3$.

\section{Results}

It has been established that cross-linked complexes of tetravalent metal-alginate are usually produced as soon as the counter ions, $\mathrm{Na}+$,of alginate macromolecule are substituted by the same quantity of cations of tetravalent metal. The metal ions that are inter-diffused, chelated the hydroxyl and carboxylate functional groups of alginate macromolecular chains through the formulation of partially coordinate and partially ionic bonds, respectively. These bonds were mediated through blocks of alginate macromolecular chains in an egg-carton like structure (Zaafaranyet al., 2009; Hassan, 1991; Vogel , 1978; Zaafarany et al., 2009; Awad\& El-Cheikh,1981; Hirst\& Rees,1965; Rees \& Scott, 1971; Schweiger, 1962). This exchange process occurs inherently and stoichiometrically, despite the mobilities, along with the valences of the two exchanging counter ions are not the same (Hellferich, 1962).

$$
4(\mathrm{Alg}-\mathrm{Na})_{\mathrm{n}}+\mathrm{n} \mathrm{M}^{4+} \rightarrow(\mathrm{Alg} 4-\mathrm{M})_{\mathrm{n}}+\left(4 \mathrm{Na}^{+}\right)_{\mathrm{n}}
$$

$$
\text { Solid aqueous solid complex aqueous }
$$

where, $(\mathrm{Alg}-\mathrm{Na}),\left(\mathrm{Alg}_{4}-\mathrm{M}\right)$ and $\mathrm{M}$ are sodium alginate, metal-alginate complex and the chelated metal ion, respectively.

The diffraction patterns of the x-rays show that the recognized alginate complexes possess amorphous nature. Pertinent bands of infrared that have delivered a substantial structural indication for the attachment mode amid these tetravalent metal cations and alginate functional groups are shown in Fig. 1. 


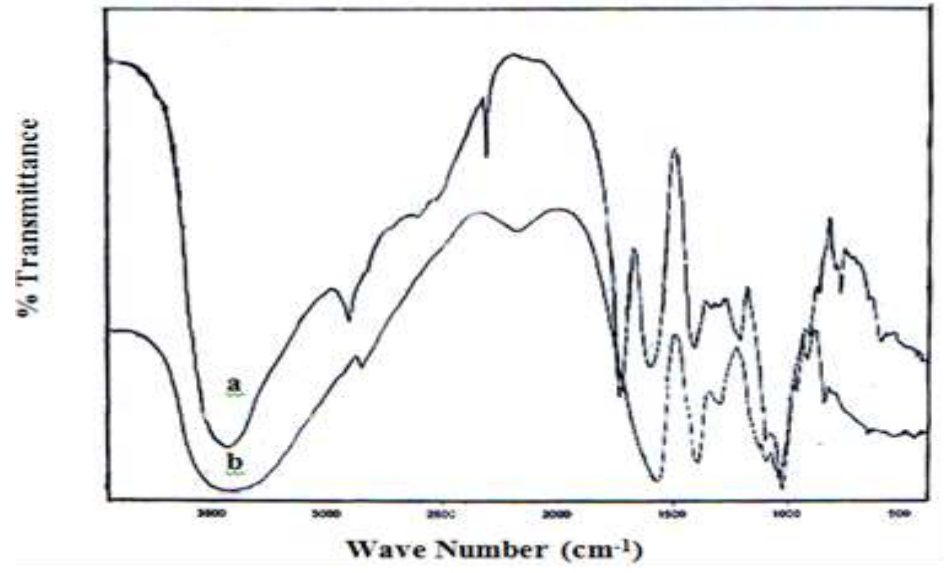

Fig. 1. Infrared Spectra of (a): Cross-Linked Ce (IV)-Alginate Complex and (b) Alginate Substrate.

The vibrational assignments of the bands showed that the bands of $v_{\mathrm{s}}-\mathrm{CO}^{2-}$ and $v_{\text {as }}-\mathrm{CO}^{2-}$ are relocated from 1600 and $1400 \mathrm{~cm}^{-1}$ in alginate to higher frequencies of 1605 and $1428 \mathrm{~cm}-1$ in the complexes indicating the barriers amid the hydroxyl and carboxylate functional groups of alginate macromolecular chains and inter-diffused Ce ${ }^{4+}$ ions (Bellamy,1966; Cozzi et al.,1968). The observation of broadband at around $3500 \mathrm{~cm}^{-1}$, which belongs to $v \mathrm{OH}$ of water (or OH-free functional groups), is also shifted to lower frequencies of $3477 \mathrm{~cm}^{-1}$ as shown in Table 1.

Table 1. FTIR Frequencies ( $\mathrm{cm}-1)$ for Sodium Alginate and Some Cross- Linked Metal-Alginate Complexes

\begin{tabular}{lccccc}
\hline Complex & $\boldsymbol{v}_{\mathbf{s}} \mathbf{O C O}$ & $\boldsymbol{v}_{\text {as }} \mathbf{O C O}$ & $\boldsymbol{v}_{\boldsymbol{O H}}$ & $\boldsymbol{v}_{\boldsymbol{M} \boldsymbol{O} \boldsymbol{O}}$ & Reference \\
\hline Na-alginate & 1400 & 1600 & 3500 & 850 & Hassan, 1993 \\
$\mathrm{Ce}^{\mathrm{IV}}$-alginate & 1424 & 1605 & 3447 & 809 & This work \\
$\mathrm{Th}^{\mathrm{IV}}$-alginate & 1419 & 1635 & 3462 & 810 & Zaafarany et al.,2009 \\
$\mathrm{Se}^{\mathrm{IV}}$-alginate & 1408 & 1629 & 3387 & 806 & Zaafarany et al.,2009 \\
\hline
\end{tabular}

Notes: $v_{\mathrm{M}-\mathrm{O}}$ : Stretching vibrations of metal-oxygen bond; $\mathrm{vOH}$ : Stretching vibrations of $\mathrm{H}$ bond of $\mathrm{OH}$; $v_{\mathrm{as}}$ : Asymmetry stretching vibrations of OCO; $v_{\mathrm{s}}$ Symmetry stretching vibrations of OCO.

The free-ligand has found to have considerably firm and well-built band at $1735 \mathrm{~cm}-1$. This can be easily allocated to the carbonyl, while extending carbonyl group vibration (Bellamy, 1966). The band displacement has also been observed at around $1742 \mathrm{~cm}-1$. This may also point out the collaboration of the carboxylate groups, within the forms of both asymmetric $\left(v_{\mathrm{as}}\right)$ and symmetric $\left(v_{\mathrm{s}}\right)$ vibration of -COO- group. In this situation, the location of the $v_{\mathrm{s}}-\mathrm{COO}^{-}$demonstrates the bridging groups of carboxylate. The electrical conductivities of Ce (IV)-alginate complex, have been estimated as a temperature function, within the circular discs structure. As shown in Fig. 2, a log o plot against 1/T of Arrhenius equation shows a complicated behavior where, two distinct conduction regions at lower and higher temperatures, separated by one transition zone is observed.

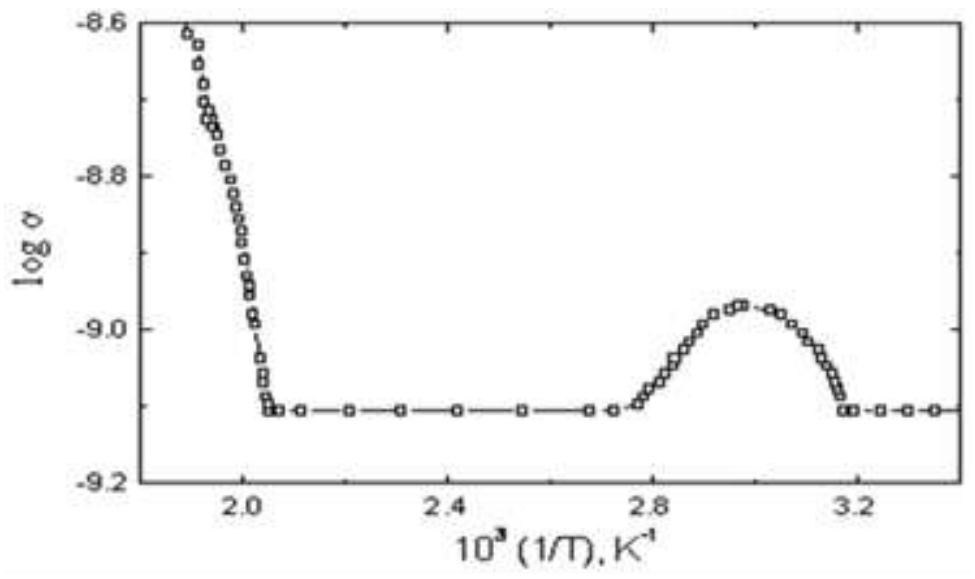

Fig. 2.A plot of Log o against 1/T of Cerium (IV) Cross-Linked Metal-Alginate Complex.

Similar behavior was observed in analogous studies of the electrical conductivity having temperature-dependence of some other cross-linked metal-alginate complexes (Hassan, 1991; Khairou\& Hassan, 2002; Zaafarany et al., 2010; Zaafarany,2014; Hassan et al., 1995; Hassan et al., 1993).The observed increment 
of electrical conductivity by the temperature increment, at early stage was recognized to the development of coordinated molecules of water in the amorphous phase by dehydration processes or formation of free-radical substrates in the studied complex(Tirkistani\& Hassan, 2012).

However, the absence of such parabolic behavior at the early stages of the measurements, for some other metal, alginate complexes despite the presence of coordination water molecules in their amorphous phases; hence, leads towards excluding the proposal of evolution of coordinated water molecules (Khairou\& Hassan, 2002) . Consequently, the observed parabolic behavior may be interpreted by the formulation of free-radical intermediates incorporating chelated cerium cations of considerably lower oxidation state $\left(\mathrm{Ce}^{3+}\right)$ rather than that of the original untreated complex (Cotton \& Wilkinson, 1972; Moller, 1967; Muller, 1967).

This suggestion was based on the possibility of relocation of electrons to the cations of cross-linked cerium metal from the alginate macromolecule. Hence, the transition zones number is mainly dependent on the probable oxidation states, which are formed during the reduction of chelated metal cations. For example, chromium (III) and iron (III) are well-known to be of one-equivalent oxidant nature (Cotton \& Wilkinson, 1972; Moller, 1967; Muller, 1967), i.e. only $\mathrm{Cr}$ (II) and Fe (II) oxidation states are formed on reduction. Therefore, the number of expected transition zones should be only one, which was observed experimentally (Zaafarany et al., 2010). Again, uranium (VI) is a multi-equivalent oxidant, which gives a various reductant states, i.e., $\mathrm{U}^{\mathrm{V}}, \mathrm{U}^{\mathrm{IV}}$ and $\mathrm{U}^{\mathrm{III}}$, respectively, through the successful mechanism of one electron transfer, within a sequence (Hassan et al., 1993).

Therefore, three parabolic shapes should be exhibited, as reported earlier (Khairou\& Hassan, 2002). On the other hand, divalent and some trivalent metal cations such as, lanthanum (III) and cerium (III) are difficult to be reduced to lower oxidation states (Cotton \& Wilkinson, 1972; Moller, 1967; Muller, 1967). Hence, it can be stated that no formation of transition zones could be expected (Zaafarany, 2014; Hassan et al., 1993). In the reflection of above experimental observations and interpretations, same mechanism of conduction is recommended in different studies, which can be followed in the present research (Hassan, 1991; Zaafaranyet al., 2010; Hassan et al., 1993).Cerium (IV) is known to be of one-equivalent nature, which in turn should manifest two parabolic zones as shown in Fig.2 (Cotton \& Wilkinson, 1972; Moller, 1967; Muller, 1967). Consequently, the increment in the values of $(\sigma)$ with the temperature increment at initial phases with respect to the studied complexes can be explained by the transfer of one-electron from alginate macromolecule to the chelated $\mathrm{Ce}^{4+}$ cations forming from free-radical intermediate substrate and metal cations of lower oxidation (Hassan et al., 2010). The phenomenon is stated as follows:

$$
\left[\left(\mathrm{RCOO}_{-}\right)_{4} \cdot \mathrm{M}^{4+}\right]_{\mathrm{n}} \rightarrow\left[(\mathrm{RCOO} .)_{(4-\mathrm{y})} \cdot \mathrm{M}^{(4-\mathrm{y})}+\right]_{\mathrm{n} 1}
$$

Where, $\mathrm{RCOO}^{-}$and $\mathrm{RCOO}$. are referred as the free alginate and its free-radical substrate, respectively, in their complexes. $\mathrm{M}$ denotes the chelated $\mathrm{Ce}^{4+}$ cations and $\mathrm{y}$ is the number of electron transferred. Of course, the dimerization of the free-radicals will lead to a decrement in the charge carriers; hence, a decrement in the electrical conductivity should be expected as observed experimentally. This dimerization is presented in below mentioned equation:

$$
\left[(\text { RCOO. })_{4-\mathrm{y}} \cdot \mathrm{M}^{(4-\mathrm{y})}+\right]_{\mathrm{n} 1}+\left[(\mathrm{RCOO})_{4-\mathrm{y}} \cdot \mathrm{M}^{(4-\mathrm{y})}+\right]_{\mathrm{n} 1}=2\left[(\mathrm{RCOO})_{(4-\mathrm{y})} \cdot \mathrm{M}^{(4-\mathrm{y})}+\right]_{\mathrm{n} 1}
$$

On the other hand, the increment in the values of $\sigma$ that was perceived at the elevated temperatures. This phenomenon could be explained through intermediate degradation for providing upsurge to the corresponding cerium oxide as the final product of oxidation (Hassan et al., 1993; Zaafarany et al., 2009; Zaafarany et al., 2009; Hassan et al., 2010; Hassan, 1992).

$$
2\left[(\mathrm{RCOO})_{(4-\mathrm{y})} \cdot \mathrm{M}^{(4-\mathrm{y})}+\right] \mathrm{n}_{1} \rightarrow \mathrm{MO}_{2}+\mathrm{xH}_{2} \mathrm{O}+\mathrm{zCO}_{2}
$$

Electrical conductivity with a number of values was acquired from a number of electrodes and they were aligned with one another. Hence, the conductance measurements reproducibility was confirmed. In other words, it means that on the behavior of electrical conductivity, there is no impact of the electrodes nature. Generally, the conductance in polymeric compounds takes place by two mechanisms of conduction, including electronic and ionic conductions. This depends on the charge carriers' nature that exists in the macromolecular chains network (Sulaneck et al., 1990).

The activation energy value can be measured as the secondary indication for the mechanism of conduction. When the value of the activation energy, Ea, is larger than unity, it means that the cationic conduction mechanism is the more prominent one, whereas, those values are usually lower than unity in case of electronic mechanism of conduction. In these cross-linked metal alginates, the activation energies can be easily increased in slopes of $\log \sigma-1 /$ T plots using the Arrhenius equation 


$$
\sigma=\sigma_{\mathrm{o}} \exp \left(\frac{-\mathrm{Ea}}{\mathrm{RT}}\right)
$$

Where, $\sigma$ is the electrical conductivity; $\mathrm{E}_{\mathrm{a}}$ is the activation energy of the charge carriers; $\sigma_{\mathrm{O}}$ is a constant.

The least squares method will be used to calculate the values, which will be summarized accompanied by complexes of the cross-linked tetravalent metal alginate, as shown in Table 2 (Zaafarany et al., 2009; Zaafarany et al., 2009). The values of activation energy are found to be less than $1.0 \mathrm{eV}$. These values are observed in order to study tetravalent metal alginate complexes in the present work which reflect the prominence of the mechanism of the electronic conduction. Again, the values of $\sigma\left(\Omega^{-1} \mathrm{~cm}^{-1}\right)$ for the listed complexes in Table 2 may indicate that the electrical conductivity increases in the order $\mathrm{Ce}^{\mathrm{IV}}-<\mathrm{Th}^{\mathrm{IV}}-<\mathrm{Se}^{\mathrm{IV}}$ - alginate complexes.

Table 2. The Activation Energies in $\mathrm{eV}$ and the Electrical Conductivity in $\Omega^{-1} \mathrm{~cm}^{-1}(290 \mathrm{~K})$ for Some Cross Linked m-Alginate Complexes.

\begin{tabular}{ccccc}
\hline Complex & $\begin{array}{c}\boldsymbol{E}_{a} \\
(\text { Initial Stage) }\end{array}$ & $\begin{array}{l}\boldsymbol{E}_{\boldsymbol{a}} \\
(\text { Final stage) }\end{array}$ & $\sigma\left(\Omega^{-1} \mathrm{~cm}^{-1}\right)$ & Reference \\
\hline $\mathrm{Ce}^{\mathrm{IV}}$-alginate & 0.28 & 0.84 & $1.04 \times 10^{-9}$ & This work \\
$\mathrm{Th}^{\mathrm{IV}}$-alginate & 0.86 & 1.20 & $2.01 \times 10^{-9}$ & Zaafarany et al.,2009 \\
$\mathrm{Se}^{\mathrm{IV}}$-alginate & 0.25 & 1.17 & $6.0 \times 10^{-9}$ & Zaafarany et al.,2009 \\
\hline
\end{tabular}

The equilibrium within ion exchange was acquired when the $\mathrm{Ce}^{4+}$ counter ions within thecomplex of metal-alginate are substituted by other cations, like $\mathrm{H}^{+}$ions. The entire process of the establishment of ion's chemical equilibrium can be expressed by the help of below mentioned equation.

$$
\begin{aligned}
& \left(\mathrm{Ce}^{\mathrm{IV}}-\mathrm{Alg}_{4}\right)_{\mathrm{n}}+\left(4 \mathrm{H}^{+}\right)_{\mathrm{n}} \stackrel{\mathrm{K}_{\mathrm{c}}}{\rightleftharpoons} 4(\mathrm{H}-\mathrm{Alg})_{\mathrm{n}}+\mathrm{nCe}^{4+} \\
& \text { Solid aqueous solid aqueous }
\end{aligned}
$$

For such heterogeneous system, the law of mass action will be applied, as shown in below mentioned equation:

$$
\mathrm{K}_{\mathrm{c}}=\left[\mathrm{H}-\mathrm{Alg}_{4} \cdot\right]_{\mathrm{n}}\left[\mathrm{Ce}^{4+}\right]_{\mathrm{n}} /\left[\mathrm{Ce}^{\mathrm{IV}}-\mathrm{Alg}_{4}\right]_{\mathrm{n}}\left[\mathrm{H}^{+}\right]_{\mathrm{n}}^{4}
$$

All solid phase activities will be considered as unity (Glasston\& Lewis, 1960; Baugh et al., 1972).

$$
\mathrm{K}_{\mathrm{a}}=\mathrm{K}_{\mathrm{c}}\left(\gamma \mathrm{Ce}^{4+} / \gamma^{4} \mathrm{H}^{+}\right)^{\mathrm{n}}
$$

During the solid phase, the activity coefficients is assumed as constant; hence, providing following relationship constant (Glasston\& Lewis, 1960; Baugh et al., 1972).

$$
\mathrm{K}_{\mathrm{a}}=\mathrm{K}_{\mathrm{c}}\left(\left[\mathrm{Ce}^{4+}\right] /\left[\mathrm{H}^{+}\right]^{4}\right)
$$

where $\mathrm{K}_{\mathrm{c}}$ is the quotient equilibrium constant; $\mathrm{K}_{\mathrm{a}}$ is the constant of thermodynamic equilibrium; $\gamma$ 's the corresponding activity coefficients.

The calculated values of the equilibrium constant were found to be 68.07 and $43.78 \mathrm{dm} 9 \mathrm{~mol}^{-3}$ at $25^{\circ} \mathrm{C}$ and $40^{\circ} \mathrm{C}$. The corresponding parameters values of the thermodynamics, for such exchange chemical equilibria were estimated of the equilibrium constant from the dependence of temperature. All of the estimated values are summarized in below mentioned Table 3. The table also incorporates the values, which are acquired for other quadrivalent metal alginate complexes (Zaafarany et al., 2009; Zaafarany et al., 2009).

Table 3. Kinetic Parameters of Chemical Equilibria for Exchange in Some Cross Linked Metal-alginate Complexes

\begin{tabular}{cclrrc}
\hline Complex & $\begin{array}{c}\mathrm{K}_{298} \\
\mathrm{dm}^{9} \mathrm{~mol}^{-3}\end{array}$ & $\begin{array}{l}-\Delta \mathrm{G}_{298}^{\circ} \\
\mathrm{kJmol}^{-1}\end{array}$ & $\begin{array}{c}-\Delta \mathrm{H}^{\circ} \\
\mathrm{kJmol}^{-1}\end{array}$ & $\begin{array}{l}-\Delta \mathrm{S}^{\circ}{ }_{298} \\
\mathrm{~J} \mathrm{~mol}^{-1} \mathrm{~K}^{-1}\end{array}$ & Reference \\
\hline $\mathrm{Ce}^{\mathrm{IV}}$-alginate & 68.07 & 10.98 & 22.83 & 39.77 & This work \\
$\mathrm{Th}^{\mathrm{IV}}$-alginate & 25.23 & 8.02 & 26.22 & 61.07 & Zaafarany et al.,2009 \\
$\mathrm{Se}^{\mathrm{IV}}$-alginate & 54.99 & 9.92 & 24.72 & 49.66 & Zaafarany et al.,2009 \\
\hline
\end{tabular}

The magnitude of the $\mathrm{K}$ values, which are obtained in the present study, may indicate that the equilibrium constant, specifically for exchange, follow the order of $\mathrm{Ce}^{4+}>\mathrm{Se}^{4+}>\mathrm{Th}^{4+}$, during their metal alginate complexes. It has been indicated from the $\Delta \mathrm{H}^{\mathrm{o}}$ negative values that the procedures of exchange are exothermic. Additionally, it has been reflected from the negative values of $\Delta \mathrm{G}^{\mathrm{O}}$ that these exchange processes are usually impulsive in nature. It was reported by (Hassan, 1993) that the interdiffused ions of metal chelate the functional groups of alginate macromolecular chains by two geometrical structures. The first type indicates the intramolecular interaction of the ions, in which functional groups are usually from the similar chains. Thereby, it can be affirmed that the planes, which incorporate the chelated metal ions are parallel with these molecular chains, i.e., 
alginate macromolecular chains. This structural arrangement is usually referred as planar geometry.

On the other hand, the second structure relates with the intermolecular association, in which the ions of metal are perpendicularly arranged with the alginate chains. It is significant to notice that the functional groups, which are involved in this process, are usually associated with different chains; hence, attaining the configuration or structural arrangement, which is normally referred as non-planar geometry (Hassan et al., 2013). In this situation, the nature and type of the attained geometry mainly relies on the coordination number and valency of the chelated metal ion in the complex. Hexavalent cations and the cations of divalent metal are referred as octahedral six coordination geometry, within their complexes. It is also established that the geometrical structure intends to chelate the functional groups through intramolecular or intermolecular association, to acquire the octahedral geometry in their complexes. Below mentioned Schemes I and II shows the geometrical configuration of their complexes.

\section{Chelation in Divalent Metal Ion Complexes}

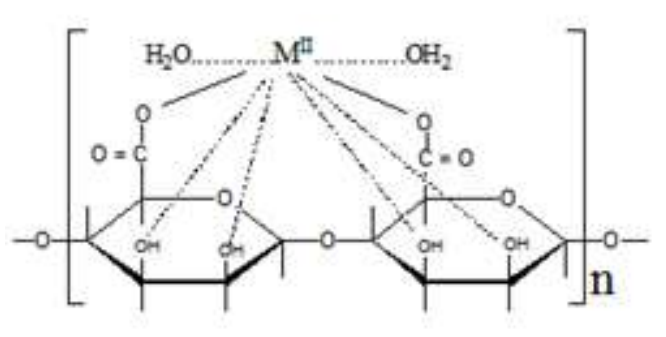

Intra-molecular association

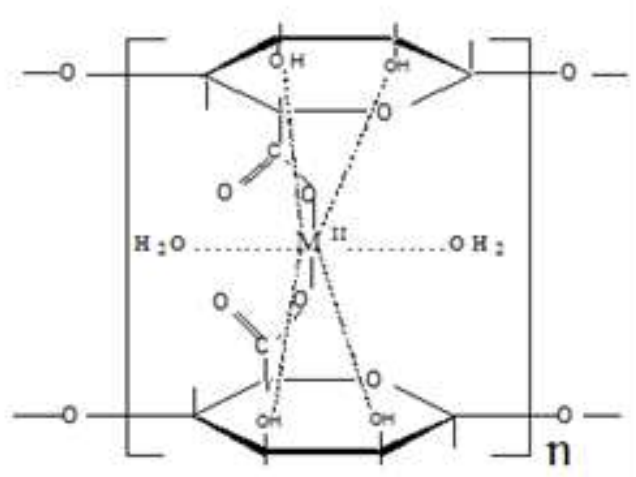

Intermolecular association

Scheme I

\section{Chelation in Uranyl Ion Complex}

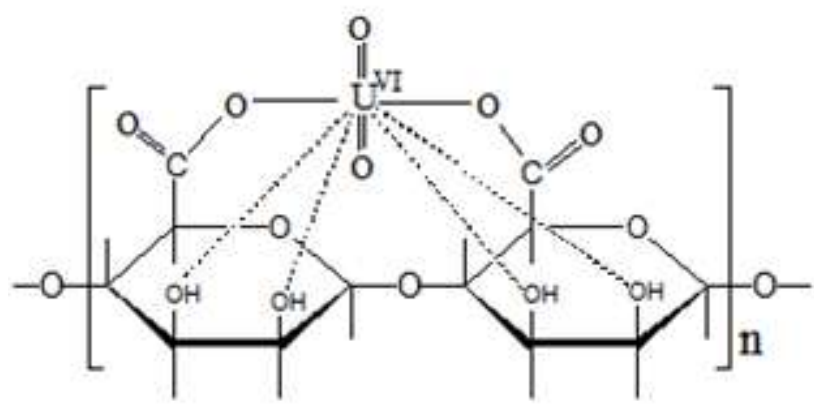

Intra-molecular association

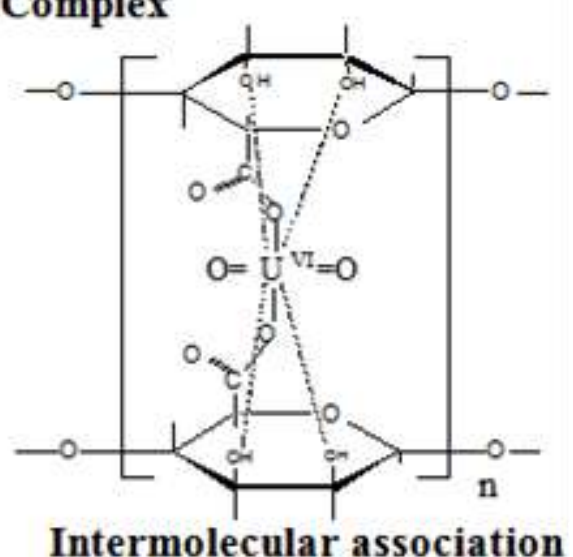

Intermolecular association

\section{Scheme II}

The priority of these two geometrical structures mainly relies on the stability and constancy of the formulated complexes. More so, the tetravalent and trivalent metal ions are forced or imposed to cross-link the functional groups of alginate macromolecule through intermolecular association type within their alginate complexes, because of having different reasons, regarding geometrical structure. Below mentioned Scheme III shows the entire phenomenon. On the other hand, the priority of the intermolecular association mechanism for chelation, while considering the case of tetravalent and trivalent metal- alginate complexes, can be easily illustrated by their capability to reduce the bond stretching, which results from the occurrence of elongation of metal-oxygen bond in case of intra-molecular association (Hassan,1993). 
Chelation in Trivalent Metal Ion

Complexes

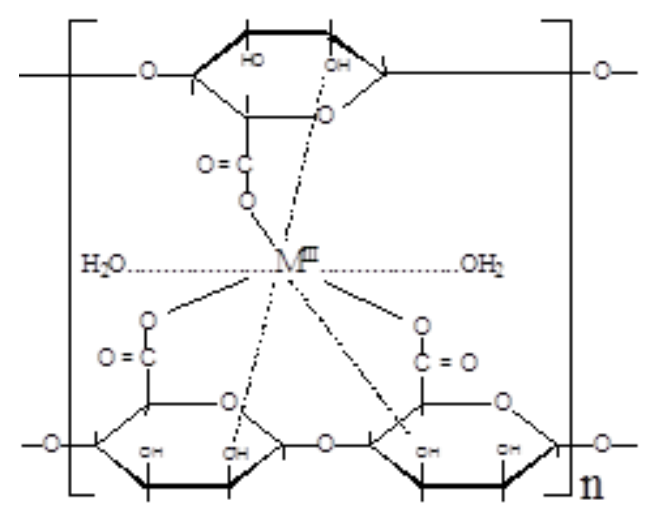

Intermolecular Association
Chelation in Tetravalent Metal Ion

Complexes

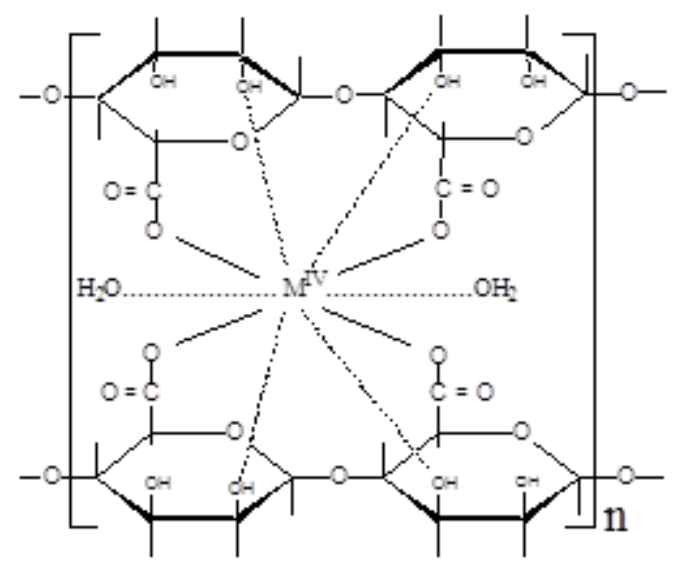

Scheme III

In the reflection of preceding explanation, the geometrical structure in metal alginate complexes can be easily attained by the help of chelation of the inter diffused metal ions with the carboxylate groups, as principal units, along with the water or hydroxyl molecules of the amorphous phase. The process intends to accomplish the coordination number of the chelated metal ion, in order to acquire more stable geometrical structure.

Charge carriers are found to increase their velocity to considerably maximum levels, in intermolecular association, as compared to intramolecular association. Hence, there is a higher expectation of electrical conductivity in the non-planar than that in the planar geometries, which is presented in Table 2 (Hassan, 1993; Thomas et al., 2006). The value of electrical conductivity lies in the range of semiconductors for monovalent, trivalent, and tetravalent metal-alginate complexes, indicating that the chelation in these metal-alginate complexes should be of intermolecular association geometry, which may confirm the provided suggestion, which is presented in Scheme III.

On the other hand, the values of the electrical conductivities for uranium (VI) - and silver (I)-alginate complexes (not listed) may indicate that the uranyl ion prefers to coordinate the functional group of alginate macromolecule through intramolecular association mechanism. On the other hand, silver (I) prefers to be chelated through intermolecular association in its alginate complex in a good accord with the results that are reported in earlier studies (Hassan, 1991; Hassan et al., 1993).

\section{Conclusion}

The cross-linked cerium (IV)-alginate complex, in the form of grains or granules has been produced in this study. During the process of experimentation, it has been established from the $\mathrm{x}$-ray diffraction trends that the alginate complexes are usually amorphous in nature. In addition to this, it has also been recognized by analyzing the spectra of infrared absorption that cerium (IV) is responsible for chelating the alginate macromolecular chains, within a complex. Moreover, the $v_{\mathrm{s}} \mathrm{OCO}$ and $\mathrm{v}_{\mathrm{as}} \mathrm{OCO}^{-}$, which has been demonstrated in this study are found to be amid the range of 1424 and $1605 \mathrm{~cm}^{-1}$. These values have revealed the fact that certain complexation amid the $\mathrm{Ce}^{4+}$ and functional hydroxyl and carboxylate groups of alginate macromolecule can be occurred within a complex. The electrical conductivity of the ordination biopolymeric cerium (IV)-alginate complex has also been estimated in the study, specifically as a function of temperature. The analysis of the processes has revealed the fact that the conductance of any complex resides in the range of the conductance, which is possessed by the semiconductors.

Different thermodynamics have also been estimated in the paper, while establishing appropriate and adequate conduction mechanism for the stability of the complex. The Arrhenius plots of log o vs.1/T have also been developed in the study, which illustrates the fact that complex behavior may take place, if two conduction regions are divided by one transition parabolic zone. The results show considerable increase in o values at the initial stages. This process was demonstrated by the development of free-radical intermediate. On the other hand, the researcher has interpreted the increase ino value, at increased temperatures, as the formation of the degradation product. Furthermore, the study has also investigated the equilibrium in heterogeneous chemical by using complexometric and titrimetric techniques. 


\section{References}

Abdel-Wahab,S. A., Ahmed, M. A., Radwan, F. A., Hassan, R. M., \& El-Refae, A. M. (1997). Relative Permittivity and Electrical Conductivity of Some Divalent Metal Alginate Complexes. Material Letters, 20, 183-188. http://dx.doi.org/10.1016/S0167-577X(96)00196-6

Ahmed, M. A., Radwan, F. A., El-Refae, A. M., Abdel-Wahab, S. A., \& Hassan, R. M. (1997). Temperature and Frequency Dependence of the Electrical Properties of Metal Alginate Complexes. Indian Journal of Physics, 71A, 395-407.

Awad, A., \& El-Cheikh, F. (1981). Electrical Resistance and Anisotropic Properties of Some Metal Alginate Gels. Journal of Colloid and Interface Science, 80, 107-112. http://dx.doi.org/10.1016/0021-9797(81)90164-8

Baugh, P. J., Lawton, J. B., \& Philips, G. O. (1972). Journal of PhysicalChemistry, 76, 658. http://dx.doi.org/10.1021/j100649a016

Bellamy, L. J. (1966). The Infrared Spectra of Complex Molecules, 2nd edn, Chapman and Hall, London, 354.

Chanda, S. K., Hirst, E. L., Percival, E. G., \& Ross A. G.(1952). Structure of Alginic Acid. Journal ofChemical Society, 1833-1837. http://dx.doi.org/10.1039/jr9520001833

Cotton, A. F., \& Wilkinson, G. (1972). Advanced Inorganic Chemistry, 3rd edn, John Wiley, New York; Moller, T, (1967). Inorganic Chemistry, Modern Asia Educational, Japan.

Cozzi, D., Desider, P. G., Leppri, L., \&Cinatelli, G. (1968). Alginic Acid, A New Thin Layer Material. Journal of Chromatography, 35, 369-404. http://dx.doi.org/10.1016/s0021-9673(01)82401-8

El-Dossouky, M., Hegazy, E. A., Dossuki, A. M., \& El-Sawy, N. M. (1986). Electrical Conductivity of Anionic Graft Copolymers Obtained by Radiation Grafting of 4-Vinylpyridine onto Poly(Vinyl Chloride). Radiation Physics and Chemistry, 27, 443-446. http://dx.doi.org/10.1016/1359-0197(86)90095-0

Glasston, S., \& Lewis, D. (1960). Elements of Physical Chemistry, 2nd ed., Van Nostrand.

Hassan, R. M. (1989). Influence of Frequency on Electrical Properties of Acid and Trivalent Metal Alginate Ionotropic Gels. A correlation between Strength of Chelation and Stability of Polyelectrolyre Gels. High Performance Polymer, 1, 275-284.

Hassan, R. M. (1991). Alginate Polyelectrolyte Ionotropic Gels. III. Kinetics of Exchange of Chelated Divalent Transition Metal Ions Especially Cobalt (II) and Copper(II) by Hydrogen Ions in Capillary Ionotropic Metal Alginate Polymembrane Gels. Journal of Materials Science, 26,5806-5810. http://dx.doi.org/10.1007/BF01130118

Hassan, R. M. (1991). Alginate Polyelectrolyte Ionotropic Gels. VII. Physicochemical Studies on Silver (I) Alginate Complex with Special Correlation to the Electrical Properties and Geometrical Structure. Colloids and Surfaces B: Biointerfaces, 60, 203-212. http://dx.doi.org/10.1007/bf01130118

Hassan, R. M. (1992). A Review on Oxidation of Uranium (IV) by Polyvalent Metal Ions. A linear Free-Energy Correlation. Coordination Chemistry Review, 27, 255-266. http://dx.doi.org/10.1080/00958979209407958

Hassan, R. M. (1993). Alginate Polyelectrolyte Ionotropic Gels. XIII. Geometrical Aspects for Chelation in Metal Alginate Complexes Related to Their Physicochemical Properties. Polymer International, 31, 81-86. http://dx.doi.org/10.1002/pi.4990310112

Hassan, R. M., Alarifi, A., Fawzy, A., Zaafarany, I. A., Khairou, K. S., Ikeda, Y., \& Takagi, H. D. (2010). Acid-Catalyzed Oxidation of Some Sulfated Polysaccharides: Kinetics and Mechanism of Oxidation of Kapp-Carrageenan by Cerium(IV) in Aqueous Perchlorate Solutions. Journal of MoecularlCatalysis A, 332, 138-144. http://dx.doi.org/10.1016/j.molcata.2010.09.009

Hassan, R. M., El-Shatoury, S. A., Mahfouz, R. M., Osman, M. A., El-Korashy, A., \& Othman, A. A. (1995). Alginate Polyelectrolyte Ionotropic Gels. VIII. Electrical Properties of Di- and Trivalent Metal Alginate Complexes Specially Iron(III) and Chromium(III) Alginate Resins. Bulletin Faculty of Science, Assiut University, 24, 141-153.

Hassan, R. M., Ikeda, Y., \& Tomiyasu, H. (1993). Alginate Polyelectrolyte Ionotropic Gels. XV. Physicochemical Properties of Uranyl Alginate Complex Especially the Chemical Equilibrium and Electrical Conductivity Related to the Coordination Geometry. Journal of Materials Science, 28, 5143-5147. http://dx.doi.org/10.1007/BF00570054

Hassan, R. M., Makhlouf, M. T., Summan, A. M., \& Awad, A. (1989). Influence of Frequency on Specific 
Conductance of Polyelectrolyte Gels with Special Correlation between Strength of Chelation and Stability of Divalent Metal Alginate Ionotropic Gels. European PolymerJournal, 25, 993-996. http://dx.doi.org/10.1016/0014-3057(89)90126-2

Hassan, R. M., Zaafarany, I. A., Gobouri, A., \& Takagi, H. D. (2013). A Revisit to the Corrosion Inhibition of Aluminum in Aqueous Alkaline Solutions by Water-Soluble Alginates and Pectates as Anionic Polyelectrolyte Inhibitors. International Journal of Corrosion, http://dx.doi.org/10.1155/2013/508596

Hellferich, H. (1962). Ion Exchange, McGraw-Hill, New York.

Hirst, E., \& Rees, D. A. (1965). The Structure of Alginic Acid. Part V. Isolation and Unambiguous Characterization of Some Hydrolysis Products of the Methylated Polysaccharide. Journal of Chemical Society, 1182-1187. http://dx.doi.org/10.1039/jr9650001182

Jing, X., Wang, Y., \& Zhang, B. (2005). Electrical Conductivity and Electromagnetic Interference Shielding of Polyaniline/Polyacrylate Composite Coatings. Journal of Applied Polymer Science, 98, 2149-2156. http://dx.doi.org/10.1002/app.22387

Khairou, K. S., \& Hassan, R. M. (2002). Temperature-Dependence of Electrical Conductivity for Cross-Linked Mono- and Divalent Metal Alginate Complexes. High Performance Polymer, 14, 93-102. http://dx.doi.org/10.1177/0954008302014001092

Kondawar, D., Mahore, R., Dahegaonkar, A., \& Agrawal, S. (2011).Microcontroller Based IR Remote Control Signal Decoder for Home Application. Advances in Applied Science Research, 2, 410-416.

Mead, C. A. (1961). Operation of Tunnel-Emission Devices. Journal of Applied Physics, 32, 646. http://dx.doi.org/10.1063/1.1736064

Muller, T. (1967). InorgChemJohn Wiely, New York.

Nandapure, S., Kondawar, S. B., Salunkhe, M. Y., \& Nandapure, A. I. (2013). Magnetic and Transport Properties of Conducting Polyaniline/nickel Oxide Nanocomposites. Advanced Materials Letters, 4, 134-140.

Rees, D. A., \& Scott, W. E. (1971). Polysaccharide Conformation. VI. Computer Model-building for Linear and Branched Pyrano- Glycans. Correlation with Biological Function. Assessment of Interresidue Forces in Aqueous Solution. Interpretation of Optical Roation in Terms of Computer Model Building in Polysaccharide Biochemistry. Journal of the ChemicakSociety B, 469-473.

Schweiger, R. G. (1962). Acetylation of Alginic Acid. I. Preparation and Viscosities of Algin Acetates. Journal ofOrganic Chemistry, 27, 1986-1991. http://dx.doi.org/10.1021/jo01052a072

Sulaneck, W. R., Clark, D. T., \& Samuelson, E. J. (1990). Science and Application of Conducting Polymers, IOP Publishing Ltd., UK, USA.

Thomas, D. P., Randal, T. C., \& Ralph, M. (2006). Molecular Models of Alginic Acid: Interactions with Calcium Ions and Calcite Surfaces. GeochimicaetCosmochimicaActa, 70, 3508-3832. http://dx.doi.org/10.1016/j.gca.2006.04.023

Tirkistani, F. A. A., \& Hassan, R. M. (2012). Kinetics and Mechanism of Non-isothermal Decomposition of Some Cross-Linked Metal-Alginate Complexes Especially Trivalent Metal-Alginate Complexes. Orient Journal of Chemistry, 11-21, http://dx.doi.org/10.13005/ojc/280235

Vogel, A .I. (1978). Text Book of Quantitative Inorganic Chemistry, 4th ed., Longman, New York.

Zaafarany, I. A. (2014). Temperature Dependence of Electrical Conductivity for Some Natural Coordination Polymeric Biomaterials Especially Some Cross-Linked Trivalent Metal Alginate Complexes with Correlation between the Coordination Geometry and Complex Stability. Journal of Advanced Chemical Engineering, 4. http://dx.doi.org/10.4172/2090-4568

Zaafarany, I. A., Khairou, K. S., \& Hassan, R. M. (2009). Physicochemical Studies on Some Natural Polymeric Complexes of Quadrivalent Metal Cations. Electrical Conductivity and Chemical Equilibria of Cross-Linked Selenium (IV)-Alginate Complex with Correlation between the Complex Stability and Geometrical Structure. Journal Saudi Chemistry, 13, 49-60.

Zaafarany, I. A., Khairou, K. S., \& Hassan, R. M. (2010). Physicochemical Studies on Some Cross Linked Trivalent Metal - Alginate Complexes Especially the Electrical Conductivity and Chemical Equilibrium Related to the Coordination Geometry. High Performance Polymer, 22, 69-81. http://dx.doi.org/10.1177/0954008308095287 
Zaafarany, I. A., Khairou, K. S., Hassan, R. M., \& Ikeda, Y. (2009). Physicochemical Studies on Cross-Linked Thorium (IV)-Alginate Complex Especially the Electrical Conductivity and Chemical Equilibrium Related to the Coordination Geometry.Arabian Journal of Chemistry, 2, 1-10. http://dx.doi.org/10.1016/j.arabjc.2009.07.011

\section{Copyrights}

Copyright for this article is retained by the author(s), with first publication rights granted to the journal.

This is an open-access article distributed under the terms and conditions of the Creative Commons Attribution license (http://creativecommons.org/licenses/by/3.0/). 